\title{
The Effect of Self-Directedness in Learing on Employment Readiness of Undergraduates in South Korea
}

\author{
Hee Yeong $\operatorname{Kim}^{1} \&$ Gi Un Kim ${ }^{2}$ \\ ${ }^{1}$ Hankuk University of Foreign Studies, Korea, Republic of \\ ${ }^{2}$ Kyungin Women's University, Korea, Republic of \\ Correspondence: Gi Un Kim, Kyungin Women's University, Korea, Republic of.
}

Received: February 12, 2018 Accepted: March 5, $2018 \quad$ Online Published: March 20, 2018

doi:10.5539/jel.v7n3p125

URL: https://doi.org/10.5539/jel.v7n3p125

\begin{abstract}
The purpose of this study is to analyze whether self-directedness in learning has positive effects on employment readiness of undergraduates. The subject of this study has little precedent research and we generated a research model. This study shows the following results: First, intrinsic motivation factor of self-directedness in learning has a positive effect on employment readiness directly. Task-solving abilities in self-directedness in learning indirectly have positive effects on employment readiness through the mediating effect of intrinsic motivation. Second, the higher the achievment orientation undergraduates have, the more negatively affected the employment readiness of undergraduates is. It means that higher achievement orientation may encourage them to explore new career paths such as graduate school or youth startup not normal employment of companies. Third, this study has the following significance: We set up and proved the relationship between subordinate variables in self-directedness in learning of undergraduates and subordinate varibles in employment readiness. We proved that the intrinsic motivation of self-directedness in learning is the most important factor to have a positive effect on the employment readiness of undergraduates.
\end{abstract}

Keywords: employability, employment readiness, self-directedness, self-directeness in learning

\section{Introduction}

Undergraduates begin to take responsibility for their own lives during their university days. As graduation day approaches, they have more matters to decide career paths by themselves. But it is not easy to be career women or men due to the lack of opportunities to get a job in South Korea (hereafter, Korea). University students have difficulties in planning their career paths and preparing for employment (Lee \& Hong, 2013). Korean undergraduates have to earn high GPA at their majors and to learn foreign languages in private educational institutes, sometimes they have to acquire information technology-related certifications to improve their employability, but company HR personnels consider another. They require candidates to have competences like interpersonal skill, problem-solving skill, self-directedness, etc (Lee \& Park, 2015).

Self-directedness is willingness to take responsibility (Botha, 2012) and inclination or tendency of students to study with their achievements of knowledge and skills. It is not easy to be educated by lecture but students can acquire it through cultivating their attitude of study in class. Self-directedness in learning (SDL) is self-starting approach in learning activities to persist in overcoming setbacks (Raemdonck, Plomp, \& Segers, 2008). SDL has become a key competence for employees (Drucker, 1993) and there have been many attempts to help students for keeping self-directedness by using educational media and information technologies. Examples of the attempts are: to apply SNS for collaborative learning, to use internet for searching the answer of unstructured problems, to engraft project-based learning at SW engineering classes with PM tools (Kim \& Na, 2016).

Self-directedness of students would be built in the dynamic and active classes but traditional classes are calm and inactive in Korea. Introducing of self-directed learning approach may cause confusion to undergraduates who are already accustomed to lecture-based and passive attitude in class from middle schools. The lecturers can change the mood of lecture-based class to dynamic and the high self-directed students would encourage to involve the class actively. We assume that self-directedness of students helps themselves to have jobs.

The purpose of this study is to identify whether self-directedness in learning affects the employability of undergraduates. To study the relation of SDL and employability, the variable factors of SDL and employment 
readiness that are controllable subset of employability are defined through a structural equation model to analyze relations between the variables. This study finds out the implication of employment readiness enhancement of undergraduates.

\section{Background}

\subsection{Self-Directedness in Learning}

The lecture-based learning approach has the advantage to deliver much knowledge to students in a short time period as rapid economic growth circumstance at the past Korea. But the Korean educational paradigm is changing now and there are attempts to convert from teacher-centered to learner-centered. Self-directed learning approach is one of attempts and is focusing on exploratory processes rather than delivered knowledges. According to a 2006 survey of the OECD's Program for International Students Assessment (PISA), the academic achievement of Korean students was ranked higher than that of the other OECD countries, while self-directed learning attitude of them was relatively lower.

According to Knowles (1975), self-directed learning is "a process in which learners take the initiative, with or without the help of others, in diagnosing their learning needs, formulating learning goals, identifying human and material resources for learning, choosing and implementing appropriate learning strategies, and evaluating learning outcomes". Self-directed learning is a process in which individuals take the initiative in diagnosing their learning needs, setting learning goals, identifying human and material resources for choosing and implementing appropriate learning strategies, and evaluating learning outcomes (Cheng et al., 2010). Self-directed learning is a process in which learners hold themselves responsible for acquiring knowledge and skills (Zimmerman \& Schunk, 1989). The definition of self-directed learning is various from scholar-to-scholar in a comprehensive sense. The terms of self-directed learning have been used variously: independent learning, self-teaching, inquiry learning, autonomous learning, self-education, self-regulated learning, etc. Brookfield (1985) argued that the terms related to self-directed learning were used diversely in order to account for several phenomena in the field of self-directed learning. Long (1992) synthesized the opinions of many scholars on self-directed learning and defined it as a cognitive process which carries out a series of meta-cognitive behavior to engage in, focus on, raise questions of, compare and contrast certain learning by learners' controlling and managing for themselves.

Self-directedness of students does not mean only grades of accomplishment but core competencies for employment and better behavior patterns through their classes. Students can improve their skills to resolve problems and have confidence to do their work. Self-directedness in learning means the abilities or the attitudes to actively solve the problems that were given in everyday life. Self-directedness in learning refers to personal character that shows the degree of a learner's needs, preference and willingness (Yoo et al., 2009). Learners take the responsibility for their own learning process and get a high performance from the class. This study assumes that undergraduates who have self-directedness in learning would have intrinsic motivation regardless of teaching methods. Lecture-based learning approach has the limit in improving job competencies such as organization understanding, leadership, communication skill, interpersonal skill, problem-solving skill, and self-directedness which are considered important by HR personnel. They try to identify job competency of job seekers during the interview and survey method.

\subsection{Employment Readiness}

Employability is a degree that job seekers feel the opportunities of employment guarantee from potential companies (Johnson, 2001) and undergraduates guess the opportunities to be guaranteed for employment before their graduations. Employability of undergraduates can be devided to subcategories. The subcategories that comprise employability are confidence, external labor market, university's reputation, and major (Rothwell et al., 2008). The external labor market is beyond the control of students, and the reputation of university and major were already decided. Confidence can be controlled and raised with continuous efforts. Rothwell et al. (2008) defined confidence as faith in their academic achievement and the degree of certitude about technology and ability that they retain.

Employment readiness is a subcategory of employability (Kim, 2009) and related to confidence and certitude of undergraduates. Prepared actions required for employment are the subcategories of employability (Fugate et al., 2004; McQuaid \& Lindsay, 2005), and the prepared actions include the acquisition of job-seeking skill, job information research, and networking among job-seekers. Undergraduates entering the job market are required to be fully prepared for employment before their university graduations. It can be very helpful for them to find jobs if this preparation can be fulfilled through the regular courses of universities. Employment readiness consists of goal-setting for job-seeking, job information research, acquisition of job-seeking skill, and preparations for careers (Kim, 2009). 


\subsection{The Relations Between Self-Directedness and Employment Readiness}

The research on the relationship between proactive personality and career success (Seibert et al., 1999) showed a positive correlation between them, and career success refers to job satisfaction, salary, and promotion of employees regardless of their organizations or jobs. Raemdonck et al. (2012) also conducted research on the self-directedness of employees, and self-directedness of employees means self-directed decision making in their learning and work-lives. The study showed that high self-directed employees have higher probabilities that they can transfer to the jobs they want and they can get promotions from within their organizations. The objects of the research (Raemdonck et al., 2012) were low-qualified employees. The research resulted by Van Loo (2005) showed that management staffs who have self-directedness increase the opportunities to keep their jobs.

We would expect that self-directed undergraduates have high employment readiness if the research results by Raemdonck et al. (2012) and Van Loo (2005) are applied to undergraduates. Coetzee \& Oosthuizen (2012) studied the relation of self-efficacy and employability satisfaction of students but they concluded that there is not significant relationship between students' self-efficacy and self-perceived employability. Self-directedness is very similar to self-efficacy and it can be meaningful to study whether self-directedness in learning would increase employment readiness for undergraduates who have employment problems.

\section{Research Methods}

\subsection{The Scales of Self-Directeness in Learning}

The measurement instruments for self-directedness in learning are Self-Directed Learning Readiness Scale (SDLRS) by Guglielmino (1977), and Self-Rating Scale of Self-Directed Learning (SRSSDL) by Williamson (2007), etc. This study uses the Self-Regulated in Learning Scale" (Yang, 2007) which was developed on the basis of meta-cognition studied by Long (1992). Yang (2007) developed questionnaires appropriate for the Korean learning environment by collecting and analyzing experts' opinions on the basis of Long's study. The measurement items are shown in table 1. The items are measured using 5-point Likert scales.

Table 1. Exogenous variables belonging to self-directedness in learning

\begin{tabular}{ll}
\hline Variables & Operational definition \\
\hline independence & The degree to which learners voluntarily plan, implement, control, and evaluate their \\
& own learning by using learning resources under the given learning circumstances. \\
& The degree to which learners can set goals, solve tasks and learn through active and \\
Task-solving abilities & new approaches under the given learning circumstances. \\
& The degree to which learners have not only confidence in the feelings of success but \\
achievement orientation & The pride and beliefs in the feelings of achievement. \\
Intrinsic motivation & understand the materials they are studying.
\end{tabular}

\subsection{The Scales of Employment Readiness}

This study extracted and reorganized from the subordinate variables of "The Instrument for Diagnosing the Employability of University Student (IDEUS)" (Kim \& Jyung, 2010) to measure the employment readiness of undergraduates. IDEUS consists of the degree of "preparation for job-seeking" (goal-setting for job-seeking, job information searching, the acquisition of job-seeking skill, preparations for careers) and "employable skills" (communication skill, resource utilization skill, problem-solving skill, interpersonal competency, change management skill). This study defined that "employment readiness" consists of goal-setting for job-seeking and job information searching which are extracted from "preparation for job-seeking". The measurement items are shown in table 2. The items are measured using 5-point Likert scales.

Table 2. Endogenous variables belonging to employment readiness

\begin{tabular}{ll}
\hline Variables & Operational definition \\
\hline goal-setting for job-seeking & $\begin{array}{l}\text { The degree to which learners concretely set their own goals for job-seeking on the basis } \\
\text { of awareness about their own interest, aptitude, personality, values. }\end{array}$ \\
job information searching & $\begin{array}{l}\text { The degree to which learners search perspectives, qualifications, required ability, } \\
\text { recruitment methods, labor market structures. }\end{array}$ \\
\hline
\end{tabular}




\subsection{Initial Research Model}

The initial research model was designed to analyze how self-directedness in learning affects employment readiness of undergraduates. The initial model (Figure 1) shows the relationship between the exogenous variables of self-directedness in learning and the endogenous variables of employment readiness. The research model which was designed using a structural equation model (SEM) has room for improvement in the process of the goodness-of-fit test of the initial model.

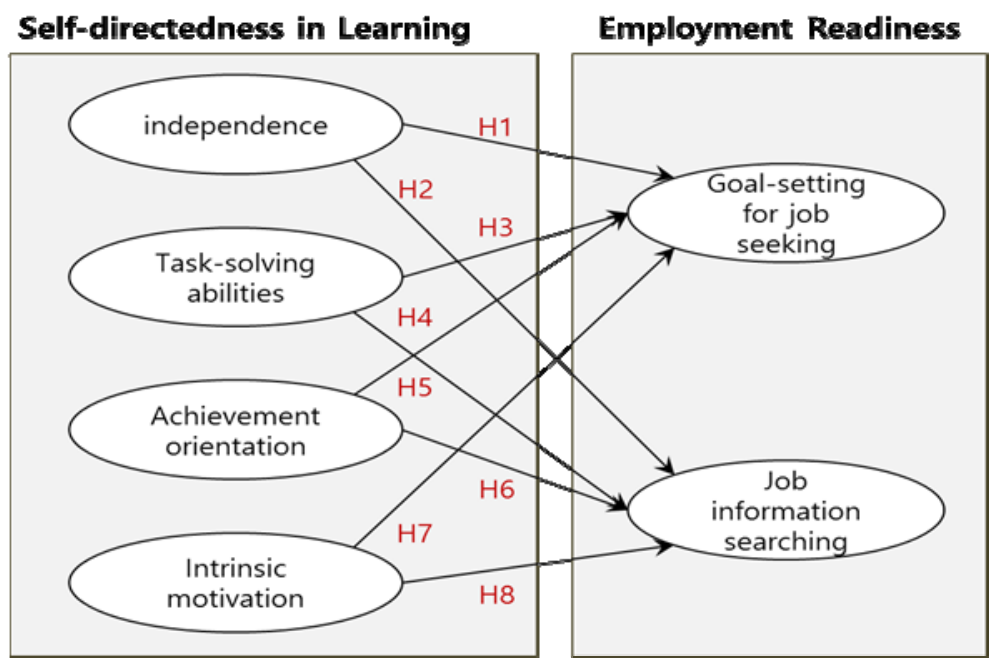

Figure 1. Initial research model

The hypotheses of this study suppose that the exogenous variables of self-directedness in learning affect positively the endogenous variables of employment readiness. Some measurement items of the questionnaire are eliminated by Exploratory Factor Analysis using SPSS 20.0. The model was improved by the result of both confirmatory factor analysis and the goodness-of-fit test of the model using AMOS 20.0.

\subsection{Adjusted Research Model and Goodness-of-Fit Test}

This study adjusts the initial research model by removing irrelevant connection lines and creating new connections among variables in process of goodness-of-fit analysis. The final research model is shown in figure 2.

Self-directedness in Learning

\section{Employment Readiness}

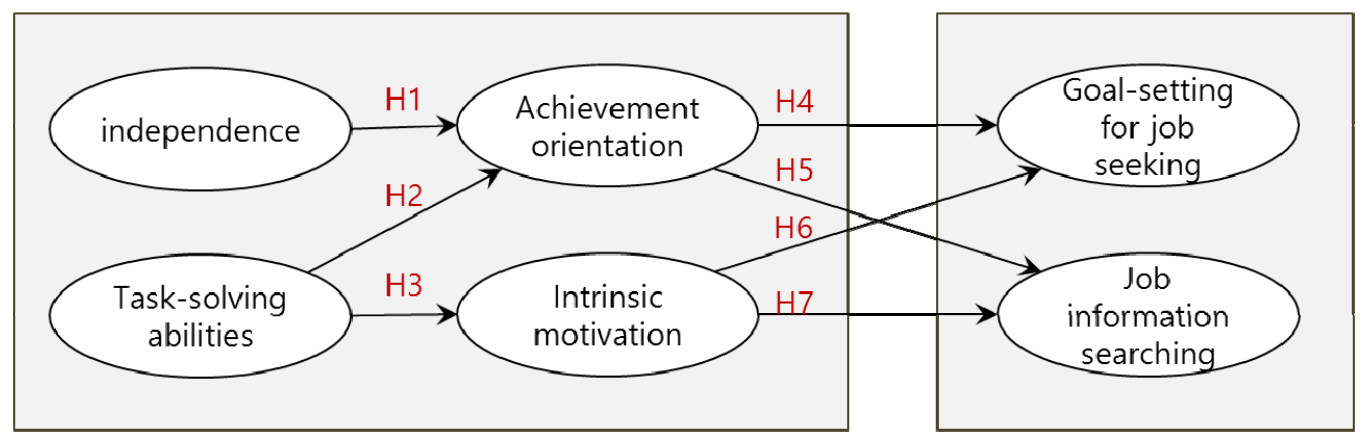

Figure 2. Adjusted research model

The goodness-of-fit of the adjusted research model shows the results in the following table 3. Four kinds of fit indices (CMIN/DF, CFI, IFI, RMSEA) were compared to the standard of model-fit and the results are fit. 
Although 3 kinds of fit indices (GFI, AFGI, NFI) fall a little short of the standard of model-fit, they are not judged unfit for our research.

Table 3. The result of the goodness-of-fit test of the adjusted model

\begin{tabular}{llll}
\hline Index & Analysis result & Standard index of model fit & Fit or good \\
\hline CMIN/DF & 2.086 & $\leq 3.0$ & Fit \\
GFI & 0.873 & $\geq 0.9$ & Good \\
AGIF & 0.836 & $\geq 0.9$ & Good \\
CFI & 0.930 & $\geq 0.9$ & Fit \\
NFI & 0.875 & $\geq 0.9$ & Good \\
IFI & 0.931 & $\geq 0.9$ & Fit \\
RMSEA & 0.064 & $\leq 0.1$ & Fit \\
\hline
\end{tabular}

The adjusted research model proposes the following hypotheses to verify the influence relationship between self-directedness in learning and employment readiness.

H1: Independence of undergraduates positively affects their achievement orientation.

H2: Task-solving abilities of undergraduates positively affect their achievement orientation.

H3: Task-solving abilities of undergraduates positively affect their intrinsic motivation.

H4: Achievement orientation of undergraduates positively affects their goal-setting for job-seeking.

H5: Achievement orientation of undergraduates positively affects their job information searching.

H6: Intrinsic motivation of undergraduates positively affects their goal-setting for job-seeking.

H7: Intrinsic motivation of undergraduates positively affects their job information searching.

\section{Results}

\subsection{The Basic Statistics on Research Variables}

This study conducted a survey of undergraduates in four universities in Seoul and the nearby areas. Total questionnaires were 272 but 7 questionnaires were excluded because of their incorrect or incomplete responses. 265 valid questionnaires were analyzed and the respondents consist of 160 male $(60 \%)$ and 105 female $(40 \%)$. The average age was 21.5 from 19 to 27 years. 174 respondents (65.6\%) are the students of social science-related departments and 91 respondents (34.4\%) are the students of engineering-related departments.

Table 4. The distribution of respondents' major

\begin{tabular}{lll}
\hline Departments & The number of respondents & Destribution \\
\hline Social science & 174 & $65.6 \%$ \\
Engineering & 91 & $34.4 \%$ \\
\hline
\end{tabular}

The distribution of the grades was as follows; the first grade (15 students, 5.7\%), the second grade (26 students, $9.8 \%$ ), the third grade (177 students, 66.8\%), and the fourth grade (47 students, $17.7 \%$ ). The age of 20 was the largest group with 23.0 percent of respondents (61 students) and the age of 21 was the second largest group with 21.5 percent of respondents (51 students).

\subsection{Exploratory Factor Analysis and Reliability Analysis}

This study conducts validity analysis and reliability analysis to investigate variables for the research model. Validity analysis is conducted in order to eliminate measurement items, which degrade internal consistency, by doing exploratory factor analysis and then to group measurement items by variables with high correlation. 
Table 5. Exploratory factor analysis and Cronbach's Alpha

\begin{tabular}{lll}
\hline Type & Variables & Cronbach's Alpha \\
\hline & independence & 0.690 \\
Exogenous Variables & task-solving abilities & 0.812 \\
& Achievement orientation & 0.778 \\
& Intrinsic motivation & 0.688 \\
\hline \multirow{2}{*}{ Endogenous Variables } & goal-setting for job-seeking & 0.844 \\
& job information searching & 0.933 \\
\hline
\end{tabular}

We performed Exploratory factor analysis to verify whether measurement items have valid factor loading value using SPSS 20.0. and eliminated measurement items less than factor loading value 0.4 because they decrease the validity of the research model. The reliability analysis of measured items was used Cronbach's alpha. After eliminating some variables, we verified that the Cronbach's alpha of each variable shows above 0.6, indicating a good reliability of variables.

\subsection{Confirmatory Factor Analysis and Reliability Analysis}

Confirmatory factor analysis is employed to test whether measurement variables are valid or not. This study analyzes the relations between the variable factors using AMOS 20.0. After removing some measurement variables that degrade validity, we get an adjusted research model, which shows $\mathrm{X}^{2}=446.437(\mathrm{df}=214$, $\mathrm{p}=0.000$ ).

\subsection{The Result of Hypothesis Test}

This study uses the method of maximum likelihood estimates in order to verify hypotheses. Regression weights and the analysis result are shown in the table 6. By the standard of C.R. (Composite Reliability), all the estimates are significant because they are above \pm 1.96 . On the basis of $p$-value, both hypothesis 1 and 4 are significant at the $\mathrm{p}<0.05$ significance level, and hypothesis 5 is significant at the $\mathrm{p}<0.005$ significance level. The other hypothesis 2, 3, 6 and 7 are significant at the $\mathrm{p}<0.001$ significance level.

Table 6. The result of hypothesis test

\begin{tabular}{|c|c|c|c|c|c|}
\hline $\begin{array}{l}\text { Hypo } \\
\text { thesis }\end{array}$ & Path & $\begin{array}{l}\text { Standardized } \\
\text { regress weight }\end{array}$ & S.E & C.R. & $\mathrm{p}$ \\
\hline 1 & independence -> achievement orientation & 0.341 & 0.130 & 2.628 & 0.009 \\
\hline 2 & task-solving abilities- $>$ achievement orientation & 0.401 & 0.079 & 5.099 & $* * *$ \\
\hline 3 & task-solving abilities -> intrinsic motivation & 0.518 & 0.153 & 3.390 & $* * *$ \\
\hline 4 & achievement orientation-> goal-setting for job-seeking & -0.428 & 0.181 & -2.370 & 0.018 \\
\hline 5 & achievement orientation $->$ job information searching & -0.750 & 0.240 & -3.126 & 0.002 \\
\hline 6 & intrinsic motivation -> goal-setting for job-seeking & 1.333 & 0.252 & 5.295 & $* * *$ \\
\hline 7 & intrinsic motivation $->$ job information searching & 1.657 & 0.318 & 5.217 & $* * *$ \\
\hline
\end{tabular}

Note. p value $* * *$ means 0.000

By the result of path analysis, all 7 hypotheses are adopted and it means that self-directedness in learning of undergraduates has an effect on employment readiness. But standard regress weights of hypothesis 4 and 5 are negative by the result of numerical analysis, it means that undergraduates who have higher achievement orientation may not set a goal for job and search job information. It can be presumed that higher achievement orientation may encourage them to explore new career paths such as graduate school and youth startups rather get a job in Korean economic environment. This study summarizes the results of the analysis as follows.

First, there is an influence relationship between the exogenous variables of self-directedness in learning: independence and task-solving abilities do not affect employment readiness directly. Achievement orientation and intrinsic motivation directly affect employment readiness and have mediated effects on independence and task-solving abilities.

Second, achievement orientation having mediated effects from independence and task-oriented abilities negatively affects both goal-setting for job-seeking and information job searching. It is interepreted that higher achievement-oriented undergraduates have more interest in exploring new direction of career. The undergraduates who have higher independence and task-solving abilities tend to have higher achievement orientation, and they search another career like going up graduation schools and start-up for future. It is needed 
to carry out additional research about why higher achievement-oriented students have more interest in exploring new career paths.

Third, intrinsic motivation having mediated effects shows that it positively affects both goal-setting for job-seeking and information job searching. Intrinsic motivation has mediated effect from task-solving abilities, not independence. It is needed further studies about why there is no correlation between independence and intrinsic motivation.

\section{Discussion and Conclusion}

This study investigated the structural relationship between undergraduates' self-directedness and their employment readiness. Adult learners' self-directedness has a strong significance to their employability attributes (Botha, Coetzee, \& Coetzee, 2015) and this study showed that undergraduates' self-directedness in learning has a positive relationship with employment readiness. The belief of students' efficacy was found to determine the level of academic accomplishment (Coetzee \& Oosthuizen, 2012) and this study found that self-directedness in learning of students would determine the accomplishment of their future.

Self-directedness is not built by the book but by the willingness and eagerness of students in the lecture. Undergraduates who want to be employed have to get self-directedness in the process of learning at their schools. In order to analyze how self-directedness in learning affects their employment readiness, we investigated precedent researches but there is little study result about the relation of self-directedness and employment readiness. This study made a new research model and used a structural equation modeling (SEM) to investigate a cause-and-effect relationship between self-directedness in learning and employment readiness. This study can have the following conclusions and implications.

First, self-directedness in learning has a positive effect on employment readiness. Especially intrinsic motivation factor of self-directedness in learning has a positive effect on employment readiness directly and task-solving abilities have a positive effect on employment readiness indirectly. Intrinsic motivation factor has mediation effect between task-solving abilities and employment readiness. Intrinsic motivation has a positive effect on goal-setting for job seeking and job information searching too.

Second, higher achievement-oriented undergraduates have a negative effect on job seeking and searching. They seek newer career paths not of employment but of establishment startup or going graduate school. We could not reveal what fields of the new career paths were concretely related to. We confined the research scope to only normal employment paths but undergraduates have many alternative career paths such as new business creation, internship abroad, and further education opportunity.

Third, this study has some significances. We set up and proved the relationship between subordinate variable factors in self-directedness in learning of undergraduates in this study. We proved that the intrinsic motivation of self-directedness in learning positively affects the employment readiness of undergraduates. This implies that educators should develop practical teaching methods to improve the intrinsic motivation of undergraduates in order to enhance the employment readiness of their students. To build up task-solving abilities for undergraduates is needed to apply new teaching methods to subjects of university. The self-directed learning method or problem-based learning is one of teaching methods for the subject curricula design for undergraduates to build up task-solving abilities.

\section{Acknowledgments}

We would like to acknowledge Bradley Ellis for his assistance in correcting this paper's English.

\section{References}

Botha, J. (2012). Graduateness, self-directedness and employability. Developing Student Graduateness and Employability: Issues, Provocations, Theory and Practical Guidelines, 385-402.

Botha, J. A., Coetzee, M., \& Coetzee, M. (2015). Exploring adult learners' self-directedness in relation to their employability attributes in open distance learning. Journal of Psychology in Africa, 25(1), 65-72.

Brookfield, S. (1985). Self-directed learning: A critical review of research. New Directions for Adult and Continuing Education, (25), 5-16. http://doi.org/10.1002/ace.36719852503

Cheng, S. F., Kuo, C. L., Lin, K. C., \& Lee-Hsieh J. (2010). Development and preliminary testing of a self-rating instrument to measure self-directed learning ability of nursing students. International Journal of Nursing Studies, 47(9), 1152-1158. https://doi.org/10.1016/j.ijnurstu.2010.02.002

Coetzee, M., \& Oosthuizen, R. M. (2012). Students' sense of coherence, study engagement and self-efficacy in 
relation to their study and employability satisfaction. Journal of Psychology in Africa, 22(3), 315-322.

Drucker, P. F. (1993). Post capitalist society. New York: Harper Business.

Fugate, M., Kinicki, A. J., \& Ashforth, B. E. (2004). Employability: A Psycho-Social Construct, Its Dimensions, and Applications, 65(1), 14-38. https://doi.org/10.1016/j.jvb.2003.10.005

Guglielmino, L. (1977). Development of the Self-. Journal of Vocational behavior Directed Learning Readiness Scale. Unpublished doctoral dissertation, University of Microfilm International, Ann Arbor, Michigan.

Johnson, C. D. (2001). In search of traditional and contemporary career success: what's an African American male to do?. The University of Georgia.

Kim, H. Y., \& Na, S. (2016). The Effects of Team-based Collaborative Learning with Social Networking Tools on Problem Solving Skills of University Students. The Journal of Educational Information and Media, 22(4), 681-703. https://doi.org/10.15833/KAFEIAM.22.4.681

Kim, S. (2009). The Development of an Instrument for Diagnosing the Employability of University Students. Graduated school of Seoul National University, Dissertation for Ph.D. in Education.

Kim, S., \& Jyung, C. (2010). The Development of an Instrument for Diagnosing the Employability of University Students. Journal of Agricultural Education and Human Resource Development, 42(2), 139-161. https://doi.org/10.23840/agehrd.2010.42.2.139

Knowles, M. (1975). Self-directed Learning: A guide for learners and teacher. NY: Association Press.

Lee, J. C., \& Hong A. J. (2013). Difference and Impact of University Students' Personal Characteristics on Self-Leadership, Career Decision-Making Self-Efficacy, Career Preparation Behavior, and Employability. The Korean Journal of Human Resource Development Quarterly, 15(3), 215-245. https://doi.org/10.18211/kjhrdq.2013.15.3.009

Lee, J., \& Park, J. (2015). Theoretical Approach to University Students Employment and the Applicability Search on NCS based Recruitment. The Journal of Employment and Career, 12(4), 139-160.

Long H. B. (1992). Learning about self-directed learning. In H. Long \& Associates (Eds.), Self-directed learning: application and research. Norman, Oklahoma: Oklahoma Research Center for Continuing Professional and Higher Education, University of Oklahoma 1.8.

McQuaid, R. W., \& Lindsay, C. (2005). The concept of employability. Urban Studies, 42(2), 197-219. https://doi.org/10.1080/0042098042000316100

Raemdonck, I., Plomp, I., \& Segers, M. (2008). Obsolete or up-to-date? The role of job characteristics and self-directed learning orientation. 4th EARLI SIG, 14.

Raemdonck, I., Tillema, H., Grip, A. D., Valcke, M., \& Segers, M. (2012). Does Self-directedness in Learning and Careers Predict the Employability of Low-Qualified Employees?. Vocations and Learning, 5(2), 137-151. https://doi.org/10.1007/s12186-011-9072-7

Rothwell, A., Herbert, I., \& Rothwell, F. (2008). Self-perceived employability: Construction and initial validation of a scale for university students. Journal of Vocational Behavior, 73, 1-12. https://doi.org/10.1016/j.jvb.2007.12.001

Seibert, S. E., Kraimer, M. L., \& Crant, J. M. (1999). What do proactive people do? A longitudinal model linking proactive personality and career success. Personnel Psychology, 54, 845-874. https://doi.org/10.1111/j.1744-6570.2001.tb00234.x

Van Loo, J. B. (2005). Training, labor market outcomes, and self-management. Doctoral Dissertation. Research Centre for Education and the Labor Market, Utercht: Utrecht University.

Williamson, S. N. (2007). Development of a self-rating scale of self-directed learning. Nurse Researcher, 14(2), 66-83. https://doi.org/10.7748/nr2007.01.14.2.66.c6022

Yang, A. (2007). An Analysis on the Influences of Emotional Intelligence, Learning Motivation, Learners 'Stress, and Self-Regulated Learning upon Academic Achievement. Graduate School of Hong-Ik University, Dissertation of Ph.D. in Education.

Yoo, M. R., Choi, Y. J., \& Kang, M. S. (2009). The Effects of PBL (Problem-Based Learning) on the Self-Directed Learning, Critical Thinking Disposition, and Problem Solving Process of Nursing Students. Journal of Korean Academy of Fundamentals of Nursing, 16(1), 46-55. 
Zimmerman, B. J., \& Schunk, D. H. (1989). Self-regulated learning and academic achievement. Berlin: Springer Science \& Business Media. https://doi.org/10.1007/978-1-4612-3618-4

\section{Copyrights}

Copyright for this article is retained by the author(s), with first publication rights granted to the journal.

This is an open-access article distributed under the terms and conditions of the Creative Commons Attribution license (http://creativecommons.org/licenses/by/4.0/). 